\title{
PERFIL REOLÓGICO DE TEXTURA DA MASSA E DO PÃO DE QUIEJO
}

\author{
Rheological profile of the texture of dough and cheese bread
}

\begin{abstract}
Antônio Vitor Machado1, Joelma Pereira²
RESUMO

O pão de queijo é um produto brasileiro de origem mineira, é um produto de panificação amplamente consumido merecendo até mesmo mérito internacional. Apesar de sua grande importância no mercado devido a seu crescente consumo, não possui padrões de padronização de produção, identidade e qualidade bem definidos. Trabalhos a seu respeito são raros, deixando a desejar mais informações sobre o produto e seus padrões de qualidade, tornando-se necessário um melhor conhecimento do papel do escaldamento nas propriedades reológicas e tecnológicas da massa e do pão de queijo para padronizar sua produção. Este trabalho foi desenvolvido no Departamento de Ciência dos Alimentos da Universidade Federal de Lavras, Minas Gerais, objetivando-se estudar o perfil reológico de textura da massa e do pão de queijo em função dos métodos de preparo empregado: com ou sem escaldamento utilizando leite ou água na formulação. De acordo com os resultados, o escaldamento demonstrou ser de grande importância na produção de massa de pão de queijo influenciando diretamente na qualidade de textura da massa e do pão de queijo produzido.
\end{abstract}

Termos para indexação: Perfil reológico, textura, massa e pão de queijo.

\begin{abstract}
Cheese bread is a Brazilian cuisine specialty originated in the Minas Gerais region. It is widely produced and consumed, and even known internationally. In spite of being widely consumed, there is no production standard, identity and defined quality. Research on the subject is rare, lacking information on the product and its quality patterns, making it necessary to have a better understanding of the effect of scalding on the rheological properties and technology of the cheese bread dough, as well as of the ingredients in the production stages. This work was carried out in the Department of Food Science at the Federal University of Lavras, Minas Gerais and one of the objectives was to study the rheological behavior of the cheese bread dough according to the methods used in preparation - with or without scalding, and using milk or water in the formulation. Another objective was to evaluate the behavior of the dough during the subsequent stages, when egg and cheese are added to the dough. The results have shown that scalding is very important in the production of cheese bread dough, having a direct influence on the physical quality and the texture of cheese bread dough.
\end{abstract}

Index terms: Rheological profile, texture, dough, cheese bread.

(Recebido em 14 de janeiro de 2009 e aprovado em 29 de março de 2010)

\section{INTRODUÇÃo}

As análises de quantificação do comportamento reológico dos alimentos e da investigação das causas químicas e estruturais determinam um assunto de grande importância para a Ciência dos Alimentos, pois o conhecimento sobre a qualidade e a integridade física dos alimentos é de grande interesse tecnológico, econômico e comercial para o desenvolvimento e processamento de inúmeros produtos (Machado et al., 2007).

A textura pode ser considerada como uma manifestação das propriedades reológicas de um alimento e constitui um atributo importante de qualidade, tem influência nos hábitos alimentares, na preferência do consumidor, afeta o processamento e o manuseio dos alimentos (Campos, 1989).

A medida precisa, consistente e objetiva da textura tem valor inestimável no campo em que as técnicas de análise de textura são empregadas tanto na monitoração do desenvolvimento do produto, quanto na identificação de problemas de processamento, tais como na falta de uniformidade da textura (Santos, 2001).

O pão de queijo é um produto de panificação obtido basicamente do escaldamento do polvilho azedo com água ou leite e óleo, amassamento com ovos, adição de queijo e assamento (Pereira, 2004). É um produto comercializado internacionalmente, mesmo assim nos dias atuais sua produção não é padronizada, tornando-se uma necessidade obter informações tecnológicas sobre suas etapas de produção, para melhorar a qualidade do pão de queijo colocado no mercado e obtendo assim referências para padronizar sua produção (Silva et al., 2009).

Este trabalho foi desenvolvido objetivando-se estabelecer o perfil reológico texturométrico da massa e do pão de queijo, buscando meios para padronizar sua fabricação, analisando as modificações reológicas que

1Universidade Federal do Rio Grande de Norte/UFRN - Rua Maria Salem Duarte, 166, Abolição II - 59619-330 - Mossoró, RN - machadoav@yahoo.com.br ${ }^{2}$ Universidade Federal de Lavras/UFLA - Departamento de Ciência de Alimentos/DCA - Lavras, MG 
ocorrem devido ao escaldamento com leite ou água e devido à adição de ovo e de queijo durante a mistura, avaliando as características de textura da massa e do pão de queijo.

\section{MATERIAL E MÉTODOS}

Este trabalho foi conduzido no Laboratório de Grãos e Cereais do Departamento de Ciência dos Alimentos, da Universidade Federal de Lavras, Minas Gerais, Brasil. O polvilho azedo utilizado foi adquirido no comércio de Lavras MG, adotando o critério da mesma marca comercial, mesmo lote e data de fabricação recente, leite integral com embalagem longa vida, ovos frescos, óleo de soja, sal, água potável e queijo tipo parmesão com 60 dias de maturação, provenientes do comércio local e foi adotado o critério de uso da mesma marca comercial e, ou mesma procedência na aquisição desses ingredientes.

Foi seguida uma formulação de pão de queijo básica contendo $250 \mathrm{~g}$ de polvilho azedo, 135,65 de leite, nas formulações com leite e 135,65g de água, nas formulações com água, 41,1g de óleo, 5,5g de sal, 23,20\% de ovo e 58,0g de queijo tipo minas padrão (Machado, 2003).

As massas de pão de queijo utilizadas neste experimento foram feitas no farinógrafo Brabender, modelo n. 810101, com misturador com capacidade para 300 g, com pás misturadoras reguladas para velocidade de rotação de 31,5 rpm. Esse aparelho foi preferido devido à constância de sua velocidade de rotação e de força de mistura. Além disso, o aparelho permite um acompanhamento da evolução da consistência da massa durante a mistura, facilitando o controle (Pereira, 2001).

O desenvolvimento da massa no farinógrafo foi realizado da seguinte maneira:

- Primeira etapa- $250 \mathrm{~g}$ de polvilho azedo foram colocados no misturador do farinógrafo; depois de iniciada a mistura, foi feito o escaldamento com leite + óleo + sal ferventes, ou água + óleo + sal ferventes, no caso das formulações sem escaldamento foi adicionado o leite + óleo + sal, ou água + óleo + sal à temperatura ambiente.

- Segunda etapa- depois de cinco minutos, foi adicionado o ovo, o qual teve a clara e a gema previamente misturadas imediatamente antes de sua adição.

- Terceira etapa- após três minutos o aparelho foi desligado e adicionado o queijo e novamente o aparelho foi ligado até que não variasse a consistência, aproximadamente três minutos, quando foi desligado e a massa foi retirada.

Após a produção da massa no farinógrafo Brabender a mesma foi moldada com o auxílio de um molde de PVC, com três centímetros de diâmetro e três centímetros de altura. O acabamento da moldagem foi feito manualmente, para que os pães adquirissem um formato redondo. As massas foram assadas em forno elétrico a $180^{\circ} \mathrm{C}$, por um tempo entre 20 e 25 minutos (Pereira et al., 1999).

A textura da massa e dos pães de queijo foram analisadas pelo analisador de textura Stable Micro System TAXT2i. Em um becker de vidro, foram colocados $150 \mathrm{~mL}$ de massa as quais foram levadas imediatamente para serem analisadas. Os teste de compressão e propriedades viscoelástica analisadas determinados pelos gráficos obtidos pelo aparelho, utilizando uma probe cilíndrica com extremidade plana com $45 \mathrm{~mm}$ de diâmetro, em alumínio.

A resistência à compressão oferecida pelos pães de queijo foi determinada com o auxílio do pistão da célula Ottawa (Pereira, 2001).

Os resultados foram expressos em $(\mathrm{N})$, a temperatura da sala de análise foi de $20^{\circ} \mathrm{C}$, e os parâmetros de configuração do aparelho foram:

- Velocidade do teste $=2,0 \mathrm{~mm} / \mathrm{s}$

- Velocidade do pré-teste $=2,0 \mathrm{~mm} / \mathrm{s}$

- Velocidade do pós-teste $=10,0 \mathrm{~mm} / \mathrm{s}$

- Força = (N)

- Distância de compressão = 10,0 mm

$\mathrm{O}$ experimento foi realizado em delineamento inteiramente casualizado, com cinco repetições, consistindo dos tratamentos com e sem escaldamento e escaldamento com leite e com água, perfazendo o esquema fatorial $(2 \times 2)$.

Os dados foram analisados pelo programa computacional Sistema para Análise de Variância SISVAR desenvolvido na Universidade Federal de Lavras, Minas Gerais (Ferreira, 2000), utilizando o índice de 5\% de probabilidade no teste de Tuckey para comparação das médias.

Foram considerados quatro tipos de tratamento: $1^{\circ}$ ) com escaldamento, utilizando uma mistura de leite, óleo e sal, adicionada ao polvilho azedo, seguida de mistura e posterior adição de ovo e depois de queijo (LCE);

$2^{\circ}$ ) sem escaldamento, utilizando uma mistura de leite, óleo e sal, adicionada ao polvilho azedo, seguida de mistura e posterior adição de ovo e depois de queijo (LSE);

$3^{\circ}$ ) com escaldamento, utilizando uma mistura de água, óleo e sal, adicionada ao polvilho azedo, seguida de mistura e posterior adição de ovo e depois de queijo (ACE);

$4^{\circ}$ ) sem escaldamento, utilizando uma mistura de água, óleo e sal, adicionada ao polvilho azedo, seguida de mistura e posterior adição de ovo e depois de queijo (ASE);

Entende-se por escaldamento a adição de uma mistura à base de leite e ou água fervente ao polvilho azedo. 


\section{RESULTADOS E DISCUSSÃO}

\section{Análise de textura da massa dos pães de queijo}

Na Tabela 1 são apresentados os valores médios da resistência à máxima força de compressão oferecida pelas massas dos pães de queijo, em função dos diferentes tratamentos.

Podemos observar na Tabela 1 que as massas dos pães de queijo obtidas do tratamento (ACE) apresentaram valor mais elevado da máxima força de compressão, seguido pelas massas dos tratamentos (LCE) e (LSE) e o menor valor da máxima força de compressão foi obtido pelas massas do tratamento (ASE). A análise estatística provou haver diferença significativa $(\mathrm{p} \leq 0,05)$, entre todos os tratamentos.

Sabe-se que o escaldamento proporciona modificações na estrutura interna dos grânulos de amido provocando a quebra de pontes de hidrogênio que mantêm o seu arranjo molecular, com isso ocorre a hidratação e inchamento dos grânulos de amido (Pizzinatto, 2000). O tratamento (ACE) resultou em uma maior hidratação do polvilho azedo apresentando massas com ótima consistência e fáceis de serem trabalhadas; o tratamento (LCE) também apresentou massas com ótima consistência e fáceis de serem trabalhadas, mas o leite resultou em uma menor hidratação do polvilho azedo conferindo um menor valor de resistência à compressão; as massas obtidas dos tratamentos sem escaldamento apresentaram-se muito moles e pegajosas, difíceis de serem manuseadas; e as massas obtidas do tratamento (ASE) foram as que apresentaram os menores valores de resistência à compressão.

As Figuras 1, 2, 3 e 4 apresentam os gráficos de textura obtidos pelo acompanhamento das massas dos pães de queijo, em função dos diferentes tratamentos As curvas resultantes dessas análises revelam que as massas dos pães de queijo apresentaram consistência fluida e cremosa, o que está indicado pela maior resistência final e pela presença de vários picos de ruptura na curva da amostra. A área negativa sob a abscissa do tempo indica a resistência oferecida pela massa quando da retirada da probe.

O tratamento (LCE) apresentou uma curva com comportamento gradativo da força de compressão indicado por um crescimento constante. O tratamento (LSE) apresentou uma maior resistência inicial da força de compressão indicada pela maior resistência da penetração da probe na amostra, aumentando gradativamente até a máxima força de compressão e apresentou uma maior resistência da retirada da probe da amostra em relação ao tratamento (LCE).

$\mathrm{O}$ tratamento (ACE) apresentou uma curva com um crescimento gradativo da força de compressão com picos de ruptura no final da máxima força de compressão, enquanto o tratamento (ASE) apresentou uma maior resistência no inicio da penetração da probe indicada por um maior valor da força de compressão inicial, apresentando picos de ruptura até a máxima força de compressão, oferecendo uma maior resistência da retirada da probe, em relação ao tratamento (ACE).

\section{Análise de textura dos pães de queijo}

Na Tabela 2 são apresentados os valores médios da máxima força de compressão oferecida pelos pães de queijo, em função dos diferentes tratamentos.

Observamos na Tabela 2 que os pães de queijo obtidos do tratamento (LSE) obteve um valor mais elevado para máxima força de compressão, seguidos dos pães de queijo obtidos do tratamento (ACE), e o menor valor da máxima força de compressão foi obtido pelos pães de queijo do tratamento (LCE). Os pães de queijo obtidos do tratamento (ASE) não foram analisados porque a força de compressão exigida por eles excedeu a $50,00 \mathrm{~N}$, força máxima alcançada pelo aparelho. A análise estatística provou haver diferença significativa $(\mathrm{p} \leq 0,05)$, entre todos os tratamentos.

Tabela 1 - Valores médios da resistência à máxima força de compressão em Newton (N) oferecida pelas massas dos pães de queijo, em função dos diferentes tratamentos.

\begin{tabular}{cc}
\hline Massas dos pães de queijo & Valores da força de compressão $(\mathrm{N})$ \\
\hline LCE & $23,38 \mathrm{~b}$ \\
LSE & $16,80 \mathrm{c}$ \\
ACE & $38,98 \mathrm{a}$ \\
ASE & $9,30 \mathrm{~d}$ \\
\hline
\end{tabular}

Médias seguidas por letras distintas, diferem entre si pelo teste de Tukey, $(\mathrm{p} \leq 0,05)$ 


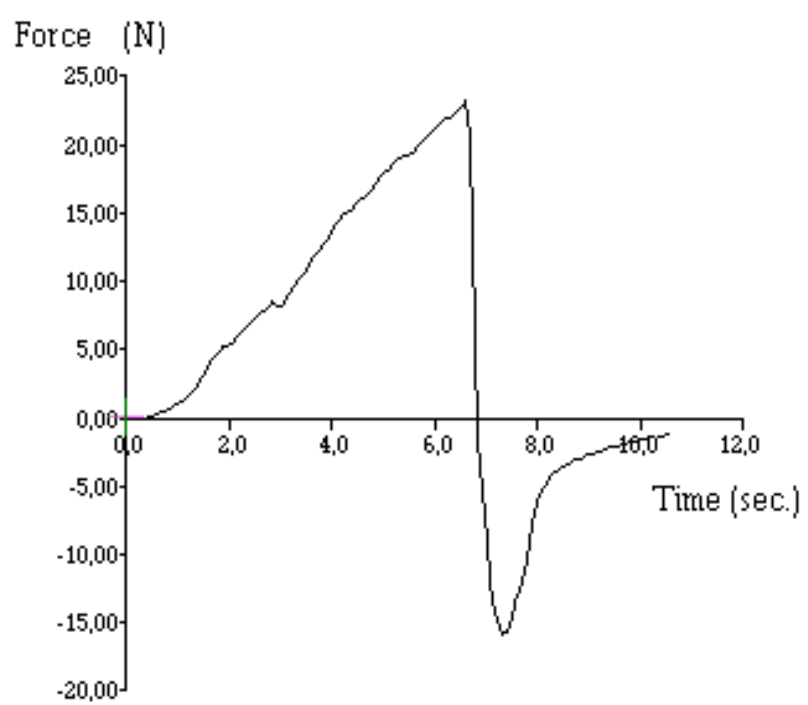

Figura 1 - Gráfico médio da máxima força de compressão obtido pelo acompanhamento da massa da formulação com leite e com escaldamento (LCE).

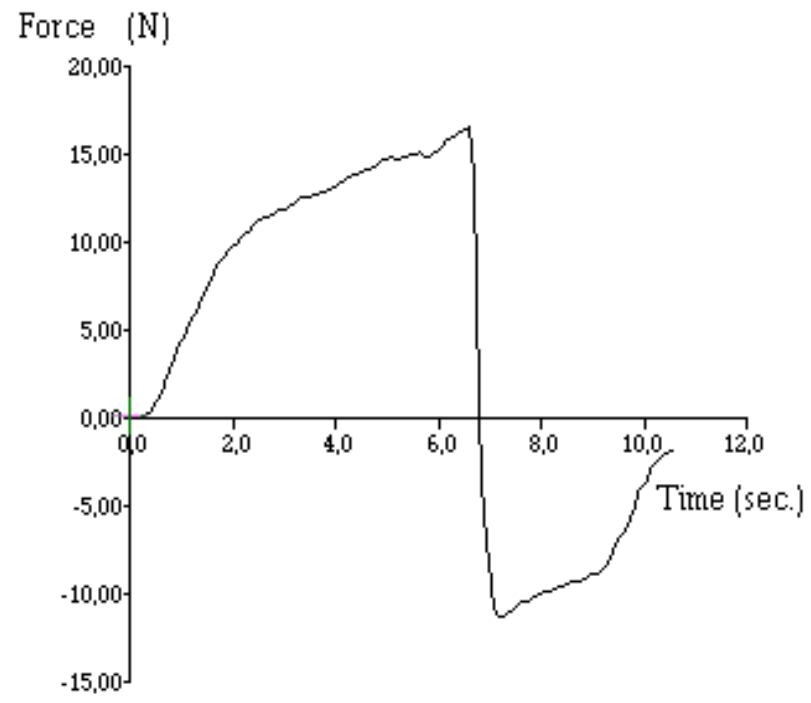

Figura 2 - Gráfico médio da máxima força de compressão obtido pelo acompanhamento da massa da formulação com leite sem escaldamento (LSE).

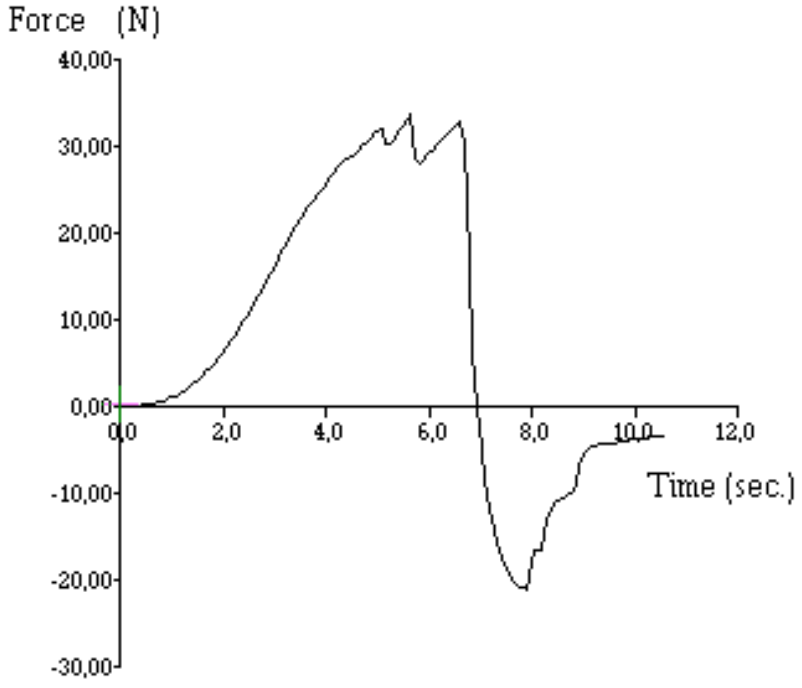

Figura 3 - Gráfico médio da máxima força de compressão obtido pelo acompanhamento da massa da formulação água com escaldamento (ACE).

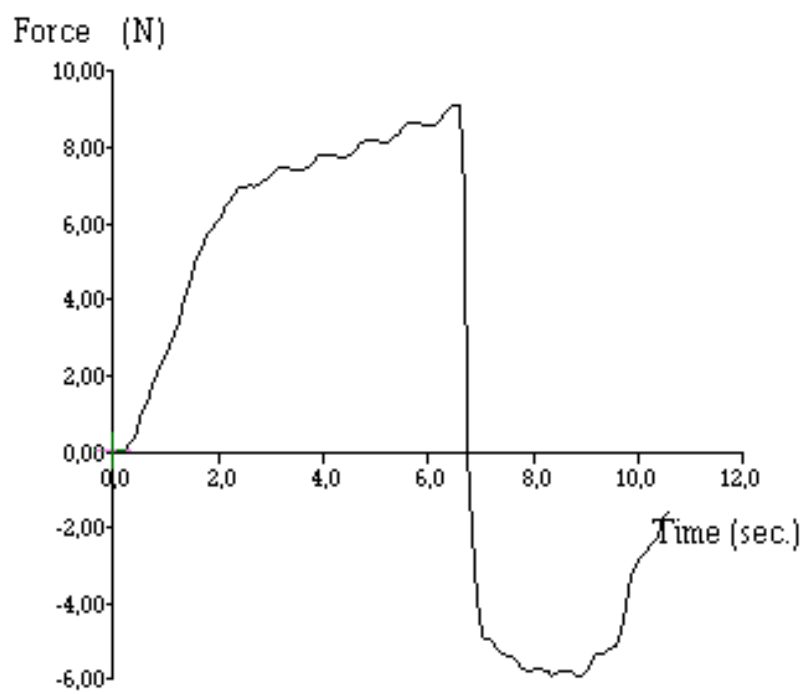

Figura 4 - Gráfico médio da máxima força compressão obtido pelo acompanhamento da massa da formulação com água sem escaldamento (ASE). 
Tabela 2 - Valores médios da máxima força de compressão em Newton $(\mathrm{N})$, oferecida pelos pães de queijo em função dos diferentes tratamentos.

\begin{tabular}{cc}
\hline Pães de queijo & Valores de força de compressão $(\mathrm{N})$ \\
\hline LCE & $16,64 \mathrm{c}$ \\
LSE & $33,70 \mathrm{a}$ \\
ACE & $28,99 \mathrm{~b}$ \\
\hline
\end{tabular}

Médias seguidas por letras distintas, diferem entre si pelo teste de Tukey, $(\mathrm{p} \leq 0,05)$.

Podemos observar que o escaldamento do polvilho azedo afetou diretamente a textura dos pães de queijo, resultando em pães de queijo mais macios. Os pães de queijo obtidos do tratamento (LCE) apresentaram-se mais macios pois o leite, devido à sua constituição química, proporcionou uma série de alterações desejáveis nos pães de queijo como melhor sabor, textura, maciez do miolo, retenção de umidade, coloração da casca e aumento de seu valor nutricional. Os pães de queijo obtidos do tratamento (ACE) apresentaram-se mais firmes com uma coloração da casca mais clara, já os pães de queijo obtidos do tratamento (LSE) apresentaram-se muito firmes.

Os resultados dos pães de queijo obtidos do tratamento (LCE) apresentaram-se próximos aos encontrados por (Pereira, 2001), que relatou valores de $16,34 \mathrm{~N}$ e $17,74 \mathrm{~N}$ para os tratamentos polvilho azedo e formulação completa.

As Figuras 5, 6 e 7 apresentam os gráficos médios da máxima força de compressão obtidos pelo acompanhamento dos pães de queijo, em função dos diferentes tratamentos.

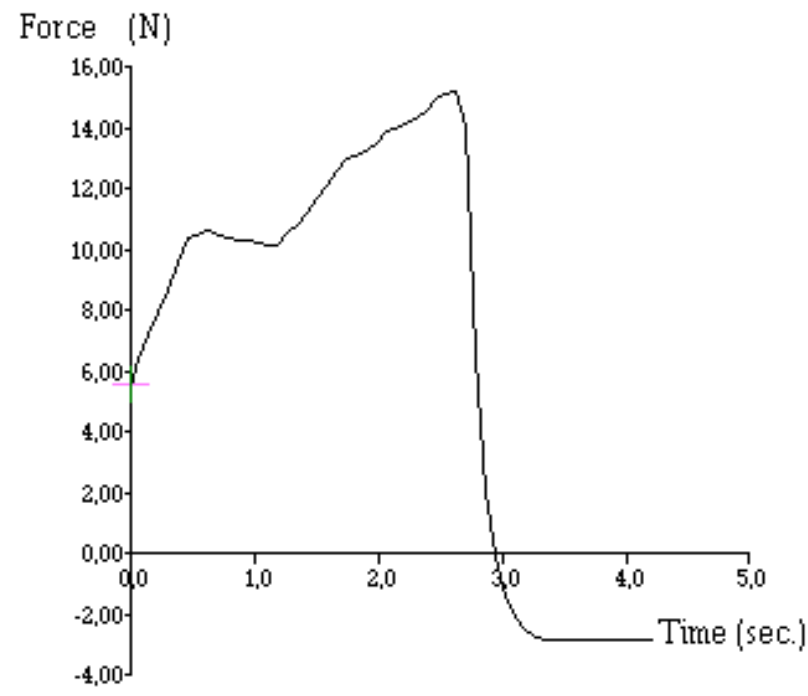

Figura 5 - Gráfico médio da máxima força de compressão do pão de queijo obtido da formulação (LCE).

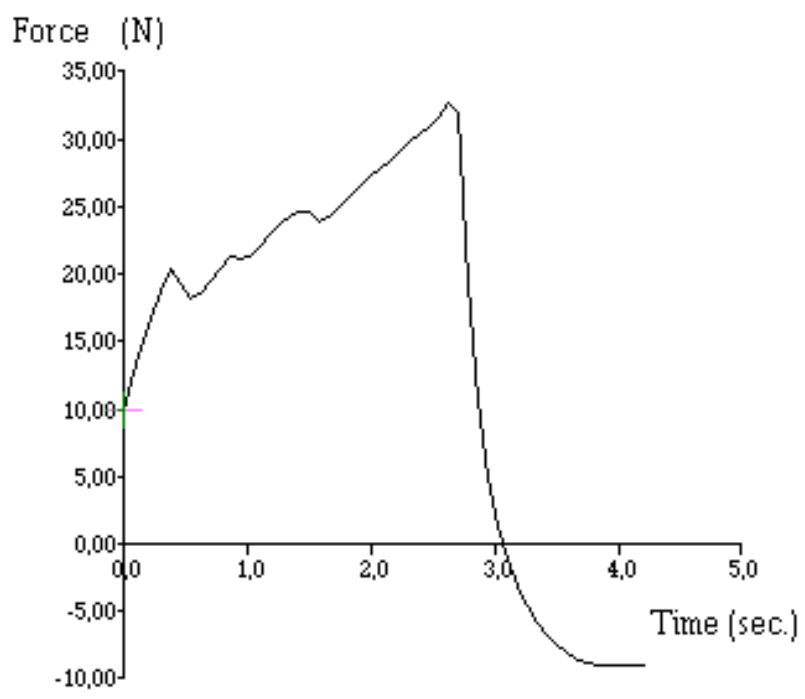

Figura 6 - Gráfico médio da máxima força de compressão do pão de queijo obtido da formulação (LSE).

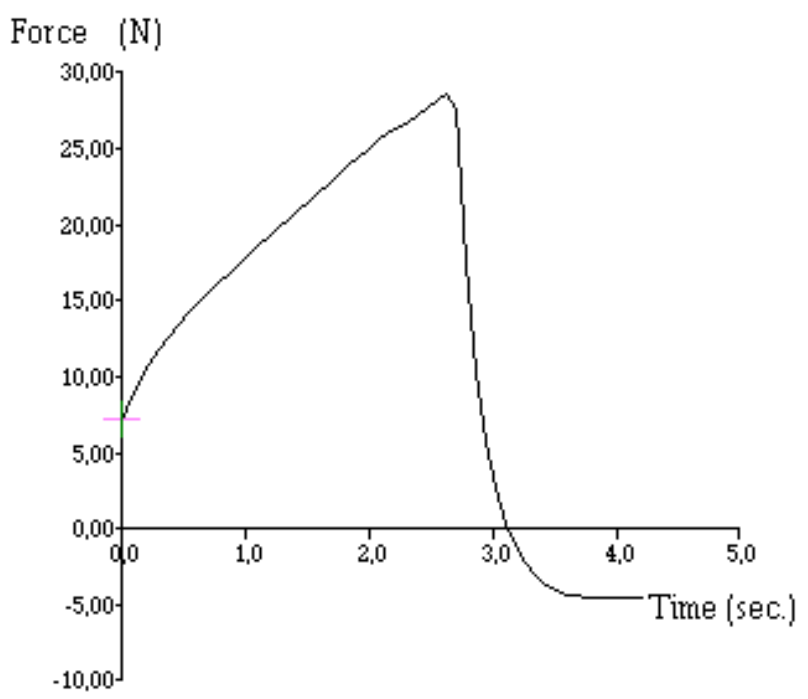

Figura 7 - Gráfico médio da máxima força de compressão do pão de queijo obtido da formulação (ACE). 
Os tratamentos (LCE) e (LSE) apresentaram perfil de curva semelhantes, o que está indicado pela presença de vários picos de ruptura na curva até atingir a máxima força de compressão revelando que os pães de queijo apresentaram casca desuniforme. $\mathrm{O}$ tratamento (ACE) apresentou uma curva com um aumento gradativo da força de compressão sem picos de ruptura, apresentando uma casca fina e lisa do pão de queijo.

\section{CONCLUSÕES}

Por meio dos resultados obtidos no presente trabalho podemos concluir que:

- O escaldamento iniciou o processo de gelatinização e teve grande influência na qualidade das massas de pão de queijo e nos pães de queijo produzidos por elas. As massas obtidas através do escaldamento apresentaram-se mais macias, com boa aparência e pouco pegajosas, sendo fáceis de serem trabalhadas apresentando melhores resultados de textura em relação aos outros tratamentos. Merece destaque o tratamento com escaldamento com mistura de leite + óleo + sal, que proporcionou massas e pães de queijo de melhor qualidade.

Os resultados sugerem que, para a obtenção de massa e pão de queijo de melhor qualidade, o escaldamento é uma etapa essencial dando-se preferência à utilização de leite na mistura de escaldamento, para obtenção de pães de queijo com melhor sabor, textura, maciez, coloração da casca e aumento de seu valor nutricional.

\section{REFERÊNCIAS BIBLIOGRÁFICAS}

CAMPOS, S.D.S. Reologia e textura em alimentos. Campinas: Instituto de Tecnologia de Alimentos, 1989. $83 p$.

FERREIRA, D.F. Programa Sisvar.exe: sistema de análise de variância. Versão 3.04. Lavras: UFLA, 2000.

MACHADO, A.V. Efeito do escaldamento nas propriedades tecnológicas da massa e do pão de queijo.
2003. 105p. Dissertação (Mestrado em Ciência dos Alimentos)-Universidade Federal de Lavras, Lavras, 2003.

MACHADO, A.V, CHAUCA-CANO, M, PEREIRA, J. Avaliação do escaldamento nas propriedades microscópicas e de cristalinidade do polvilho azedo. In: SIMPÓSIO LATINO AMERICANO DE CIÊNCIA DE ALIMENTOS SLACA, 7., 2007, Campinas. Anais... Campinas: Unicamp, 2007. CD- ROM.

PEREIRA, J. Caracterização química, física, estrutural e sensorial do pão de queijo. 2001. 222p. Tese (Doutorado em Ciência dos Alimentos)-Universidade Federal de Lavras, Lavras, 2001.

PEREIRA, J, CIACCO, C.F, VILELA, E.R, PEREIRA, R.G.F.A. Função dos ingredientes na consistência da massa e nas características do pão de queijo. Ciência e Tecnologia de Alimentos, Campinas, v.24, n.4, p.494-500, 2004.

PEREIRA, J, CIACCO, C.F, VILELA, E.R, TEXEIRA, A.L. de S. Féculas fermentadas na fabricação de biscoitos: estudo de fontes alternativas. Ciência e Tecnologia de Alimentos, Campinas, v.19, n.12, p.287-293, maio/ago. 1999.

PIZZINATTO, A. Processo de fabricação de pão de queijo. Ingredientes, Formulação e Processo, v.1, p.87101,2000 .

SANTOS, J.A.F. Análise da textura garante consistência uniforme. Food Ingredientes, South America, v.11, p.2829, mar./abr. 2001.

SILVA, R.P.G, PEREIRA, J, NERY, F.C, VILELA, E.R. Efeito do congelamento nas características físicas e químicas do pão de queijo. Ciência e Agrotecnologia, Lavras, v.33, n.1, p.207-212, 2009 